\title{
Metadata Correction: Epidemiology of Surgical Site Infections With Staphylococcus aureus in Europe: Protocol for a Retrospective, Multicenter Study
}

Sibylle C Mellinghoff ${ }^{1}$, MD; Jörg Janne Vehreschild ${ }^{1}$, MD; Blasius J Liss ${ }^{2 *}$, MD; Oliver A Cornely ${ }^{1,3^{*}}$, MD

${ }^{1}$ Department I of Internal Medicine, University Hospital of Cologne, University of Cologne, Cologne, Germany

${ }^{2}$ Department I of Internal Medicine, Helios University Hospital Wuppertal, Wuppertal, Germany

${ }^{3}$ Cluster of Excellence, Cellular Stress Responses in Aging-Associated Diseases, University of Cologne, Cologne, Germany

* these authors contributed equally

Corresponding Author:

Sibylle C Mellinghoff, MD

Department I of Internal Medicine

University Hospital of Cologne

University of Cologne

Kerpener St 62

Cologne, 50937

Germany

Phone: 4922147832884

Fax: 492214781435226

Email: sibylle.mellinghoff@uk-koeln.de

\section{Related Article:}

Correction of: https://www.researchprotocols.org/2018/3/e63/

(JMIR Res Protoc 2019;8(1):e10712) doi: 10.2196/10712

The authors of the paper "Epidemiology of Surgical Site Infections With Staphylococcus aureus in Europe: Protocol for a Retrospective, Multicenter Study" (JMIR Res Protoc 2018;7(3):e63) made a mistake in the final stage of proofreading. In the affiliations list, Dr Liss's affiliation was incorrectly listed as "Department I of Internal Medicine, University Hospital of Cologne, University of Cologne, Cologne, Germany”. Instead, his affiliation should read "Department I of Internal Medicine, Helios University Hospital Wuppertal, Wuppertal, Germany".

The correction will appear in the online version of the paper on the JMIR website on January 7, 2019, together with the publication of this correction notice. Because this was made after submission to PubMed, PubMed Central, and other full-text repositories, the corrected article also has been resubmitted to those repositories.

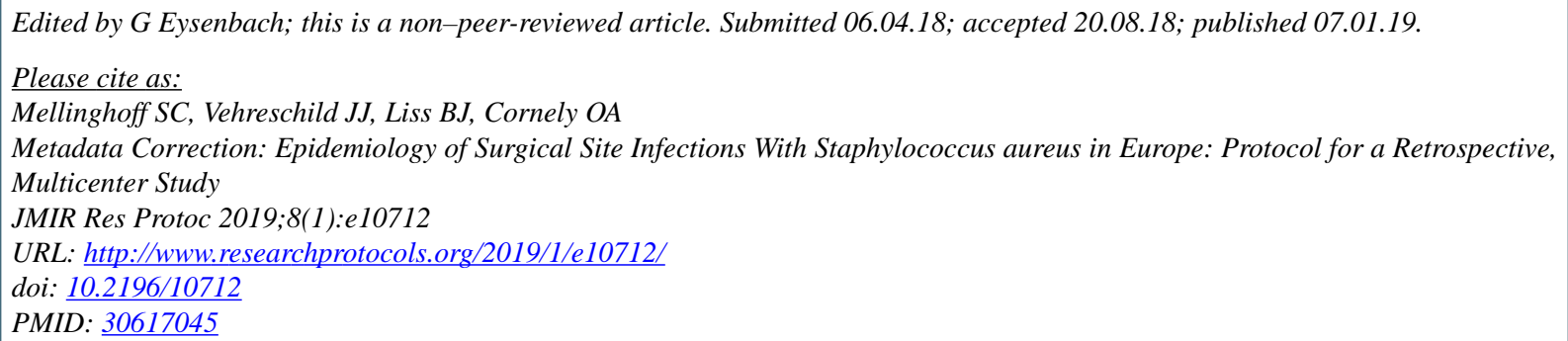

(CSibylle C Mellinghoff, Jörg Janne Vehreschild, Blasius J Liss, Oliver A Cornely. Originally published in JMIR Research Protocols (http://www.researchprotocols.org), 07.01.2019. This is an open-access article distributed under the terms of the Creative Commons Attribution License (https://creativecommons.org/licenses/by/4.0/), which permits unrestricted use, distribution, and 
reproduction in any medium, provided the original work, first published in JMIR Research Protocols, is properly cited. The complete bibliographic information, a link to the original publication on http://www.researchprotocols.org, as well as this copyright and license information must be included. 